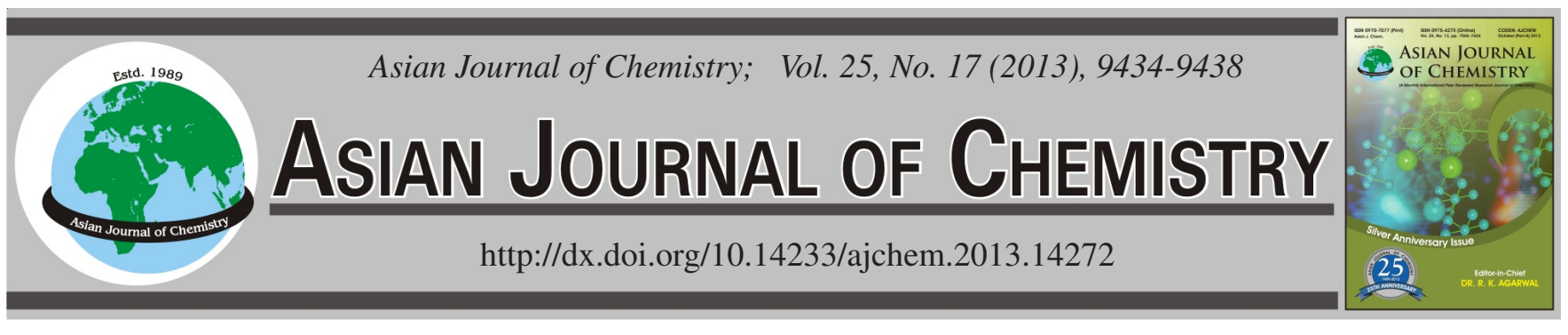

\title{
Cyclometallic Zirconium Compound in Ring Opening Polymerization of L-Lactide to Biodegradable Polylactide
}

\author{
Ruhi Haque ${ }^{1, *}$, Mohin SAXena ${ }^{1}$, S.C. Shit ${ }^{2}$ and Asokan Pappu ${ }^{1}$
}

${ }^{1}$ CSIR-Advanced Materials and Processes Research Institute, Bhopal-462 064, India

${ }^{2}$ Central Institute of Plastics Engineering and Technology, Plot No. 630, Phase-IV, GIDC, Vatva, Ahmedabad-382 445, India

*Corresponding author: E-mail: ruhi_haq2003@yahoo.com

(Received: 20 December 2012;

Accepted: 1 October 2013)

AJC-14199

\begin{abstract}
Polylactide found potential as a substitute of non renewable resources. It is biodegradable and biocompatible polymer. Ring opening polymerization of polylactide has gained the importance in pharmacological, biomedical and environmental fields. In the present study, L-lactide was successfully polymerized with synthesized zirconium catalyst i.e., $\mathrm{N}$-methyl benzyl amine zirconium chloride compound in bulk and in solution (THF) and the effect of monomer to catalyst ratio on the molecular weight of polymer were studied. Catalytic compound is an organometallic five membered cyclic compound, synthesized by cyclometallation process. It was observed that cyclometallic zirconium compound can effectively polymerize L-lactide to high molecular weight polylactide. Cyclometallic compound and polylactide was characterized by FT-IR, ${ }^{1} \mathrm{H}$ and ${ }^{13} \mathrm{C}$ NMR, CHNS techniques. Molecular weight was determined by GPC and thermal study was done by TGA-DSC. Surface morphology and shape was evaluated via FESEM.
\end{abstract}

Key Words: Biodegradable polymer, Ring opening polymerization, Polylactide, Catalyst, Cyclometallation.

\section{INTRODUCTION}

Polylactide (PLA) is one of the most readily available thermoplastic polyester that is derived from renewable resources such as corn, beet and sugar. Polylactide is $100 \%$ biodegradable, can be recycled over 7-10 times ${ }^{1-4}$. Polylactide has been produced commercially and is used in packaging, agriculture, automotive, electronics sector, furniture, house ware sector, medical sector (absorbable sutures, in tissue engineering and controlled drug delivery $)^{5-6}$. More research effort is being directed toward finding methods of addressing the weakness of PLA without compromising its biodegradability. Theses polymers are appropriate in place of conventional plastics in large scale applications while exhibiting reduced environmental impact. Polylactide have high physicomechanical properties which make it suitable for product development. Polylactide showing tensile strength, flexural strength and impact strength 50-70 MPa, 60-70 MPa and 2.6 to $2.7 \mathrm{Kj} / \mathrm{m}^{2}$, respectively $y^{7-10}$.

Low molecular weight PLA can obtained by polycondensation and high molecular weight PLA can obtained by ring opening polymerization of lactide. Fig. 1 summarized the entire polymerization route. Ring opening polymerization of lactide can be carried out in melt, bulk, or in solution and by cationic, anionic and coordination-insertion mechanisms depending on the catalyst ${ }^{11-13}$. The choice of initiator system, co-initiator as chain control agent, catalyst concentration, monomer-to-initiator ratio and polymerization temperature and time significantly affect the polymer properties ${ }^{14-18}$. In the present study, organometallic cyclic compound was synthesized and used as catalyst for ring opening polymerization of Llactide to polylactide at different monomer to catalyst ratio. The effect of different monomer to catalyst ratio in bulk and in solution on molecular weight distribution was also studied.

Cyclometallation is a highly attractive and versatile synthetic method to produced organometallic compounds, because it permits to understand significant aspects of the metal-mediated activation of unreactive bonds mainly $\mathrm{C}-\mathrm{H}$ bond. Cyclometallic compounds have been used in inorganic transformations and catalysis ${ }^{19-24}$. They have been also utilized in other area of materials science for example in sensors, in anticancer agents and for other bioorganometallic applications ${ }^{25-29}$. Cyclometallation reaction can be achieved into two main steps, comprising the bonding of the metal center by the (hetero) atom $\mathrm{N}, \mathrm{P}, \mathrm{O}$, etc. and the $\mathrm{C}-\mathrm{H}$ bond activation. Influencing factors are metal precursor, donor group and $\mathrm{C}-\mathrm{H}$ bond activation. Requirement for a metal moeity is suitable for inducing cyclometallation i.e. providing a coordination site for atom bonding. Thus in the first step, attachment of the ligand via $\mathrm{M}-\mathrm{N}$ interactions was occurred and in the second step, the $\mathrm{C}-\mathrm{H}$ bond activation process is facilitated by strongly basic ligands at the metal moeity ${ }^{30}$. 


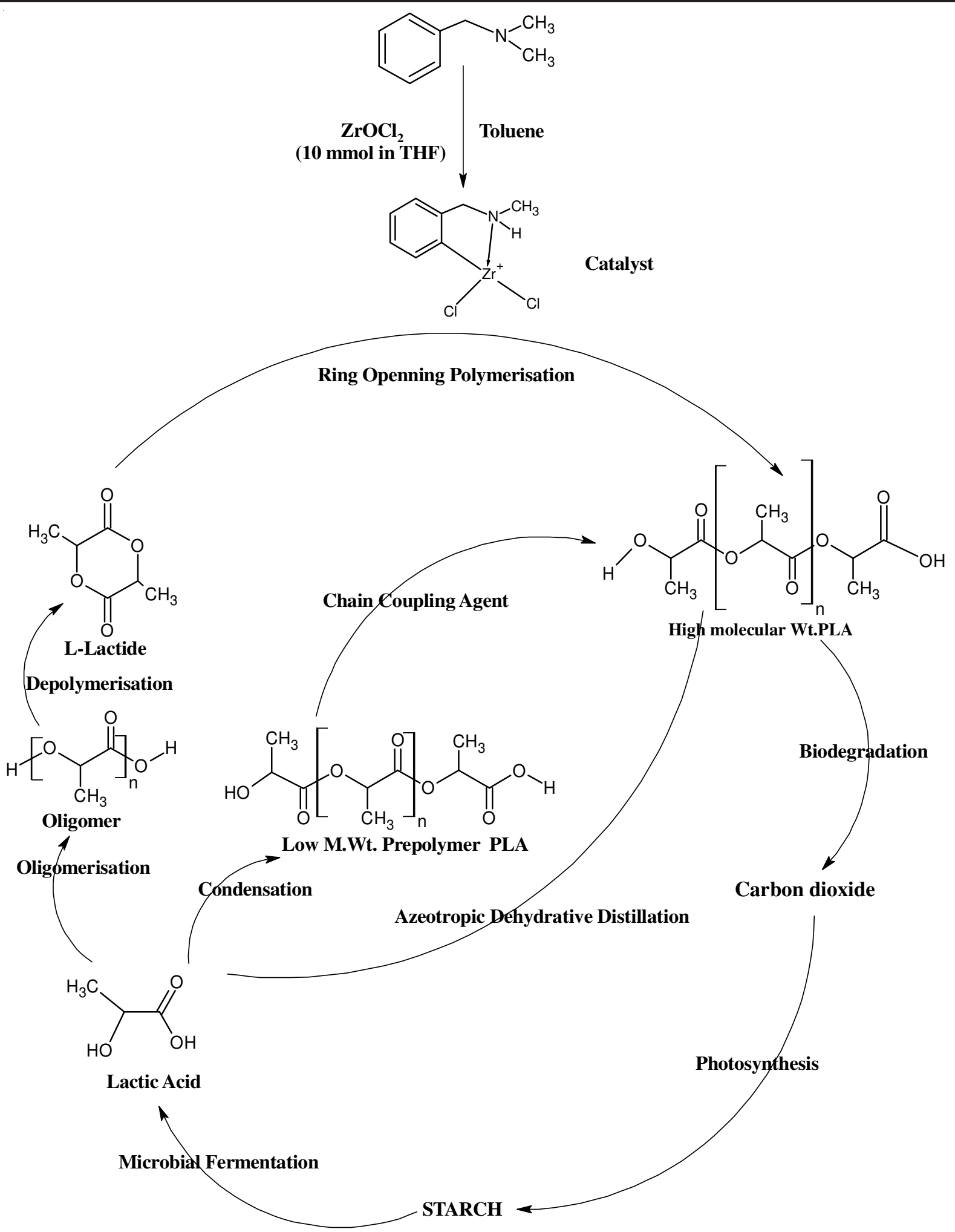

Fig. 1. Flow chart of ring opening polymerization

In the present study, organometallic five membered cyclic amine compound was synthesized and utilized as catalyst for ring opening polymerization of L-lactide to polylactide. Cyclometallic compound and PLA was characterized by FTIR, ${ }^{1} \mathrm{H}$ and ${ }^{13} \mathrm{C}$ NMR and CHNS techniques. Molecular weight was determined by GPC and thermal study was done by TGADSC. Surface morphology and shape was evaluated via FESEM.

\section{EXPERIMENTAL}

4,4'-Methylene bis(N,N-dimethylaniline), L-Lactide were purchased from Alfa Aesar and only L-lactide was twice recrystallized in diethyl ether before use. Reagents like toluene, THF, zirconium oxychloride, acetyl chloride, $\mathrm{KOH}$, ethyl alcohol, methanol, tetrahydrofuran (THF), acetone, dichloromethane, chloroform, diethyl ether, etc. are commercially 
available. All the solvents used for synthesis were purified and dried prior to use.

${ }^{1} \mathrm{H}$ NMR and ${ }^{13} \mathrm{C}$ NMR spectra were recorded on a Brucker instrument using TMS or dimethyl sulfoxide as internal standard. A Perkin Elmer model 883 IR spectrometer was used for recording the FT-IR spectra. The elemental analysis was carried out with a Perkin Elmer 2400 Series II CHNS/O analyzer. The UV-visible spectra were recorded on a Shimadzu Model 1601 UV-Visible spectrophotometer. High resolution electron micrographs (FESEM and SEM) were obtained with a JEOLJEM 2100 (Japan) electron microscope operating at an accelerating voltage of $200 \mathrm{kV}$ at room temperature. Gel permeation chromatography (GPC) was used for determination of molecular weights of the polymers, with a Malvarn Viscotek GPC Instrument equipped with a Shodex RI-101 refractometer detector. The flow rate was set at $0.8 \mathrm{~mL} \mathrm{~min}^{-1}$ using THF as the mobile phase and the elution of the sample was monitored with RI detector. Polystyrene used as standards.

General methods: Evaluation of thermal crystalline characteristics of polymer was determined according to F2625-10. Viscosity measurements were done according to ASTM D2857-95 (Reapproved 2007). Hydroxyl value is the number of milligrams of potassium hydroxide equivalent to the acetyl chloride consumed by $1 \mathrm{~g}$ of sample. The ester value is the number of $\mathrm{mg}$ of $\mathrm{KOH}$ needed to saponify the ester in $1 \mathrm{~g}$ of a sample which can be determine by subtracting the acid value from the saponification value of that polymer. Saponification value was determined by following ASTM: D464-05. Acid value is the mass of $\mathrm{KOH}$ in milligrams that is needed to neutralize one gram of chemical substance which can be calculated by following this formula.

$$
\text { Acid value }=\mathrm{A} \times \mathrm{N} \times 56.1 / \mathrm{W}
$$

$\mathrm{A}=\mathrm{mL}$ of $0.1 \mathrm{~N} \mathrm{KOH}$ consumed for sample

$\mathrm{N}=$ Normality of $\mathrm{KOH}$

$\mathrm{W}=$ Weight in gram of the sample

\section{RESULTS AND DISCUSSION}

Synthesis of catalyst $\mathrm{N}$-methyl benzyl amine zirconium oxychloride compound: A solution of N,N-dimethyl benzyl amine $(15 \mathrm{~mL}, 10 \mathrm{mmol})$ in THF $(20 \mathrm{ml})$ was added to a suspension of zirconium oxychloride $(0.32226 \mathrm{~g}, 1 \mathrm{mmol})$ in THF $(30 \mathrm{~mL})$. Solution was heated for the purpose of dissolution and was centrifuged at $17000 \mathrm{rpm}$ for $1 \mathrm{~h}$ at $-20{ }^{\circ} \mathrm{C}$ after the stirring for $24 \mathrm{~h}$ at room temperature. Light greyish powder was obtained in high yield after washing 3 times with THF, extracting with toluene. Synthesized compound is used as initiator for ring opening polymerization of L-lactide to polylactide.

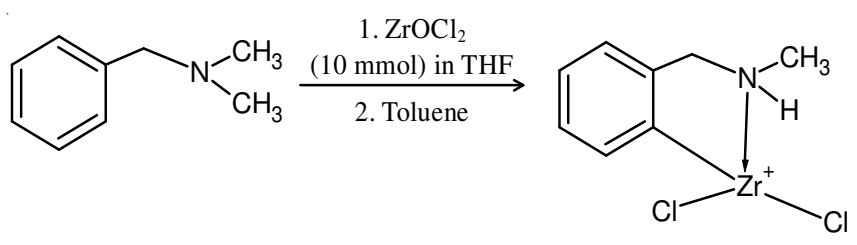

$\mathrm{N}, \mathrm{N}$-dimethyl benzyl amine $\mathrm{N}$-methyl benzyl amine zirconium chloride

Scheme-I: Synthesis of N-methyl benzyl amine zirconium chloride compound
Characterization of $\mathrm{N}$-methyl benzyl amine zirconium chloride: $\mathrm{C}_{8} \mathrm{H}_{10} \mathrm{NZrCl}_{2}$. F.W: 282.30 . Yield $=90 \%$. m.p.: 345 ${ }^{\circ} \mathrm{C}$; UV (THF solvent, $\lambda_{\max }$ ): $280 \mu \mathrm{m}$ (due to aromatic amine); FTIR $\left(\mathrm{KBr}, \mathrm{v}_{\max }, \mathrm{cm}^{-1}\right): 3395.92(\mathrm{~N}-\mathrm{H}$ stretching of secondary Amine); 3008.86 (C-H stretching of aromatic benzene ring); 2936.70 (C-H stretching in $\mathrm{CH}_{2}$ ); 2677.86 (C-H stretching in $\mathrm{CH}_{2}$ ); 2575.65, 2522.91, 2479.97, 2365.19 (zwitter ion); 1585.66 (N-H band), 1460 (C-H band in methylene), 1417 $(\mathrm{C}=\mathrm{C}$ stretching in aromatic nuclei): 1285,1171 (C-N stretching) 747 (ortho-disubstitution of benzene ring): 1065, 1021, 945, $832(\mathrm{~N}-\mathrm{H}$ wag); $801.32(\mathrm{C}=\mathrm{C}$ ring stretching aromatic character); ${ }^{1} \mathrm{H} \mathrm{NMR}\left(\mathrm{CDCl}_{3}, 400 \mathrm{MHz}\right) \delta$ ( $\delta$ in ppm): $\delta 7.66$, (dd, 1H, Ar-H benzenoid gp), 7.280 (dd, 1H, Ar-H benzenoid gp), 3.16, 3.010, 3.768, 3.891 (singlet, 2H, Ar- $\mathrm{NH}_{2}$ ); 2.261 (singlet, $\left.2 \mathrm{H}, \mathrm{Ar}-\mathrm{CH}_{2}-\mathrm{Ar}\right) .{ }^{13} \mathrm{C} \mathrm{NMR} .\left(\mathrm{CDCl}_{3}, 400 \mathrm{MHz}\right) \delta$ (ppm): 131.02, 130.70, 129.34, 128.76 (aromatic carbon atom), 59.41 (singlet, - $\mathrm{CH}_{2}$ ) , 41.51, 40.13 (doublet, $2 \mathrm{H},-\mathrm{CH}_{2}-\mathrm{NH}$ ); 39.92, 39.71, 39.50, 39.29, 39.09, 38.88 (sexate, ${ }^{1} \mathrm{H}, \mathrm{Ar}_{-} \mathrm{CH}_{2-}$ $\mathrm{NH}-\mathrm{CH}_{3}$ ).

The formation of $\mathrm{N}$-methylaniline zirconium chloride confirmed by FT-IR, ${ }^{13} \mathrm{C}$ NMR characterization. $3396 \mathrm{~cm}^{-1} \mathrm{~N}-\mathrm{H}$ stretching for secondary amine with $3009 \mathrm{~cm}^{-1} \mathrm{C}-\mathrm{H}$ stretching of aromatic group confirmed the aromatic secondary amine. $\mathrm{C}-\mathrm{H}$ stretching of $-\mathrm{CH}_{2}$ - group confirmed by $2937 \mathrm{~cm}^{-1}$. Zirconium metal bonded at meta position with respect to $\mathrm{N}$ atom confirmed by 832 and $801 \mathrm{~cm}^{-1}$ bands that N, P, O element substituted element at $\gamma$-position from it and also bonded with that element through coordination bond. Hence formed zwittor ion confirmed by stretching bend at $2365 \mathrm{~cm}^{-1}$. ${ }^{1} \mathrm{H}$ NMR chemical shift at around 7 confirms the aromatic benzenoid group. Zwittor Ar-N-(H)- $\mathrm{CH}_{3}$ confirms at $3.891 \mathrm{ppm}$. Ar- $\mathrm{CH}_{2}$-Ar confirm singlet at $2.261 \mathrm{~cm}^{-1} \cdot{ }^{13} \mathrm{C}$ NMR spectra at the $40.45 \mathrm{ppm}$ show the presence of $-\mathrm{NH}\left(\mathrm{CH}_{3}\right)$ group.

Several structural features are apparent from the NMR data: a) ${ }^{1} \mathrm{H}$ NMR spectrum exhibits a signal at $3.891 \mathrm{ppm}$ assigned for the $\mathrm{NH}$ proton, indicating that the ligand remains protonated after coordination and this $\mathrm{NH}$ can also be seen in the IR spectrum which appears at $3395.92 \mathrm{~cm}^{-1}$; b) ${ }^{13} \mathrm{C} \mathrm{NMR}$ spectrum exhibits signals at $40.45 \mathrm{ppm}$ assigned to the $\mathrm{NH}\left(\mathrm{CH}_{3}\right)$. Rehder et al. ${ }^{31,32}$ have shown similar results, whereas the reaction between $\left[\mathrm{VOCl}_{2}(\mathrm{thf})_{2}\right]$ and the tetradentate dithiolate-diamine ligand is a coupled reaction in that both complexation and oxidation of the ligand occurs. Results are agreed with the literature ${ }^{1-8}$ that the presence of elements $\mathrm{N}, \mathrm{P}$, $\mathrm{O}$ bonded to the metal centre and substitution of metal centre occurs at $\gamma$-position to the $\mathrm{N}$ atom confirms, the synthesized compound is five membered cyclic compounds. Cyclometallation may started by precoordination of $\mathrm{N}$ atom of $\mathrm{N}, \mathrm{N}$-dimethyl benzyl amine with the zirconium oxychloride. This coordination enhanced the density of electron at metal centre and this influenced the $\mathrm{C}-\mathrm{H}$ bond activation mechanism of cyclometallation. This leads to synthesize five membered cyclic ring compounds follow the cyclometallation with $\mathrm{C}-\mathrm{H}$ bond activation mechanism. Zirconium oxychloride bonded at meta position with Ar- $\mathrm{NH}-\left(\mathrm{CH}_{3}\right)$ and also bonded with $\mathrm{N}$ atom of secondary amine with the removal of a molecule of water and form a compound N,N-dimethyl benzyl amine zirconium chloride (Scheme-I) which is used further as catalyst for ring opening polymerization of L-lactide to PLA. SEM 
pictures in Fig. 2 showed that compound is of nano size (27.3$44.8 \mathrm{~nm}$ ) which may enhance the rate of reaction of polymerization.

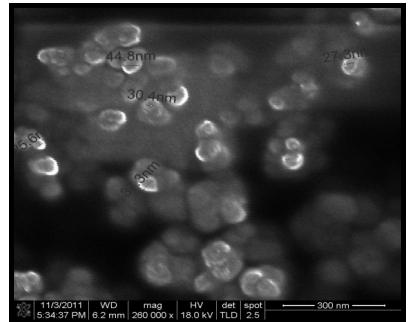

(a)

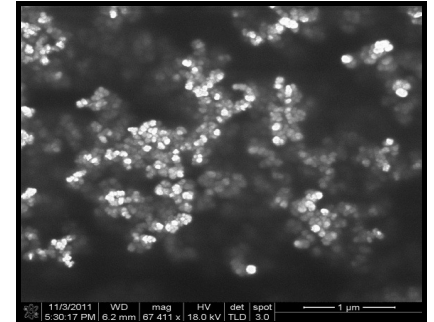

(b)

Fig. 2. SEM of N-methylaniline zirconium chloride cyclometallic compound

Synthesis of polylactide (PLA) by N-methylaniline zirconium chloride cyclometallic compound

Bulk and in solution polymerisation: Bulk polymerization and in solution polymerization of L-lactide was done at different ratio $(100,200,500$ and 1000) of monomer to $\mathrm{N}$-methylaniline zirconium chloride cyclometallic compound using as catalyst at $140{ }^{\circ} \mathrm{C}$ under nitrogen atmosphere in an Erlnmayer flask for $1 \mathrm{~h}$ without solvent and with solvent $(2 \mathrm{~mL}$ THF). After the completion of polymerization, the obtained polymer was dissolved in $4 \mathrm{~mL} \mathrm{CHCl}_{3}$ and precipitated in excess of diethyl ether. The obtained polymer was dried in vacuum oven at $40{ }^{\circ} \mathrm{C}$.<smiles>C[C@H]1OC(=O)[C@@H](C)OC1=O</smiles>

L-lactide<smiles>CN1Cc2ccccc2C(Cl)(Cl)C1</smiles>

Synthesis of PLA by N-methyl benzyl amine zirconium chloride compound

Characterization: Polylactide. Yield $=90 \%$. m.p.: 170$180{ }^{\circ} \mathrm{C}$; UV (THF Solvent, $\lambda_{\max }$ ): $285-295 \mathrm{~m} \mu$ (due to $\mathrm{n}$ to $\pi^{*}$ transition of carbonyl group). FTIR ( $\left.\mathrm{KBr}, \mathrm{v}_{\max }, \mathrm{cm}^{-1}\right): 1739.02$ $v(\mathrm{C}=\mathrm{O}), 2992.02 \mathrm{v}_{\mathrm{as}}\left(\mathrm{CH}_{3}\right), 2944.02 \mathrm{v}(\mathrm{COC})$ and 866.58 $v(\mathrm{C}-\mathrm{COO}) ; 1374.11$ (bending frequencies for $\delta_{\mathrm{s}}\left(\mathrm{CH}_{3}\right), 1453.29$ (bending frequencies for $\delta_{\text {as }}\left(\mathrm{CH}_{3}\right)$ ) and $751.97 \mathrm{~cm}^{-1}$ [bending frequencies for $\delta(\mathrm{C}=\mathrm{O})]$. ${ }^{1} \mathrm{H} \mathrm{NMR}\left(\mathrm{CDCl}_{3}, 400 \mathrm{MHz}\right) \delta(\mathrm{ppm})$ : 5.205, 5.171, 5.136, 5.101 (quadrate, ${ }^{1} \mathrm{H}$, -CO-CHMe-O); 4.380, 4.349 (doublet, $2 \mathrm{H}$, residual lactide), 1.591, 1.556, 1.504 (doublet, $3 \mathrm{H},\left(-\mathrm{CO}-\mathrm{CH}-\mathrm{CH}_{3}-\mathrm{O}-\right.$ ).

Polylactide's characteristic stretching frequencies for $\mathrm{v}(\mathrm{C}=\mathrm{O}), \mathrm{v}_{\mathrm{as}}\left(\mathrm{CH}_{3}\right), \mathrm{v}_{\mathrm{s}}\left(\mathrm{CH}_{3}\right), \mathrm{v}(\mathrm{COC})$ and $\mathrm{v}(\mathrm{C}-\mathrm{COO})$ are at $1739.02,2992.02,2944.02,1123.39$ and $866.58 \mathrm{~cm}^{-1}$, respectively. Bending frequencies for $\delta_{\mathrm{s}}\left(\mathrm{CH}_{3}\right), \delta_{\text {as }}\left(\mathrm{CH}_{3}\right)$ and $\delta(\mathrm{C}=\mathrm{O})$ have been identified at 1374.11, 1453.29 and $751.97 \mathrm{~cm}^{-1}$ respectively. Representative IR spectra of PLA synthesized by catalyst $\mathrm{N}$-methyl benzyl amine zirconium chloride are represented in Fig. 3(a).

Physical and chemical properties: Bulk polymerization by zirconium catalyst leads high molecular weight PLA with respect to solution polymerization. In bulk polymerized PLA showed quite higher $\mathrm{M}_{\mathrm{n}}$ at $100 \mathrm{M} / \mathrm{I}$ ratio i.e. 26400 and 22903 at $1000 \mathrm{M} / \mathrm{I}$ ratio. $\mathrm{M}_{\mathrm{w}}$ of bulk polymerized PLA is from 26400 to 22903. In solution polymerized PLA has low $\mathrm{M}_{\mathrm{n}}$ (24100 to 23092) and $M_{w}$ (31780-23092). GPC results showed a decrement in $\mathrm{M}_{\mathrm{n}}$ and $\mathrm{M}_{\mathrm{w}}$ with the increased molar ratio both in bulk

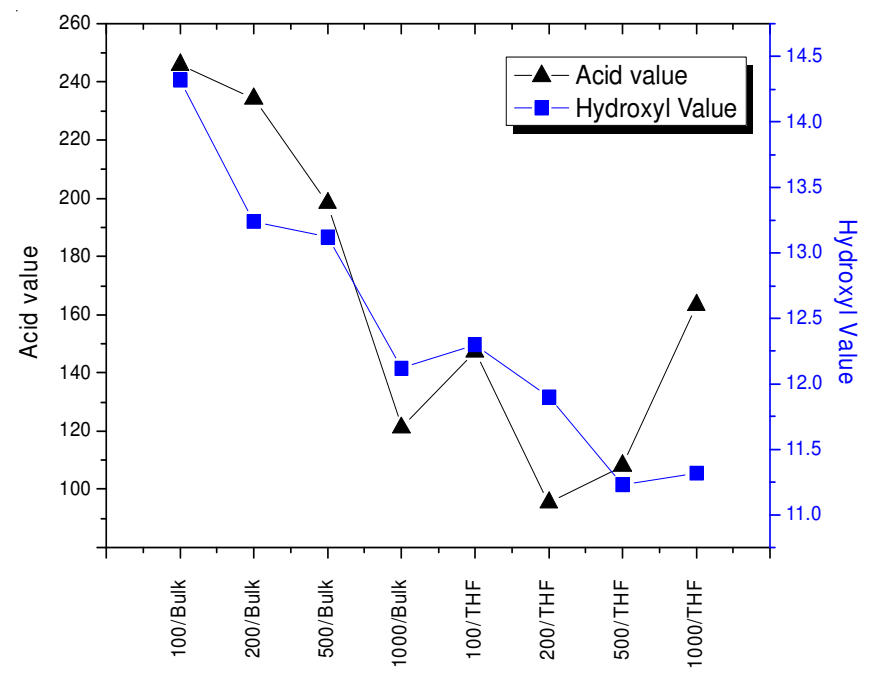

(a)
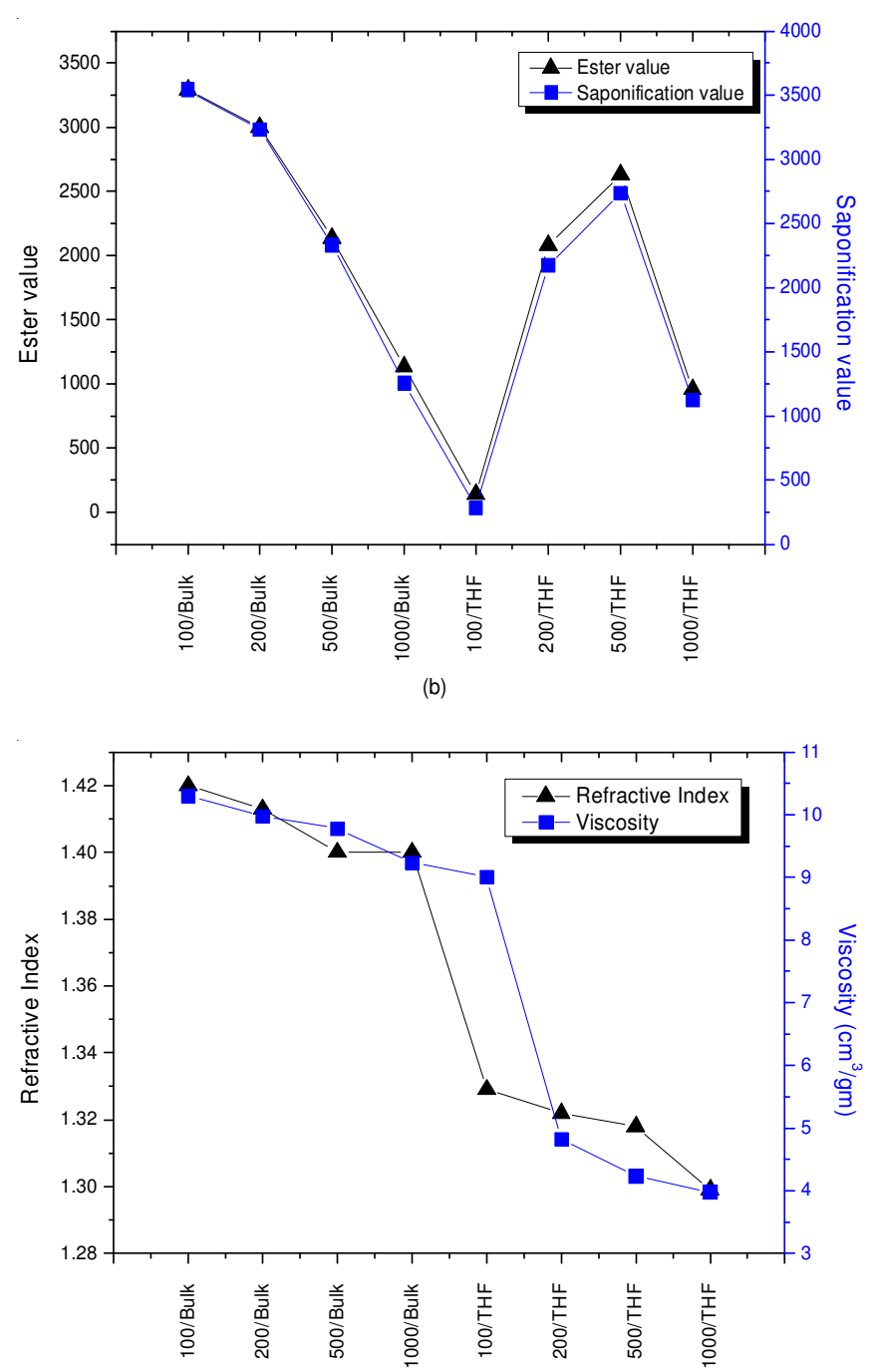

(c) 
TABLE-1

PROPERTIES OF POLYLACTIDE PREPARED BY CATALYST N-METHYL BENZYL AMINE ZIRCONIUM CHLORIDE

\begin{tabular}{|c|c|c|c|c|c|c|c|}
\hline Molar ratio & $\mathrm{T}_{\mathrm{g}}$ & Onset Temp. & Crystallinity (\%) & Yield $(\%)$ & $\mathrm{M}_{\mathrm{n}}$ & $\mathrm{M}_{\mathrm{w}}$ & PDI \\
\hline 100/Bulk & 54 & 120.34 & 118.450 & 93.37 & 26400 & 26500 & 1.003 \\
\hline 200/Bulk & 52 & 119.34 & 114.450 & 88.30 & 25893 & 25490 & 0.984 \\
\hline 500/Bulk & 53 & 117.34 & 111.460 & 87.30 & 23233 & 25223 & 1.085 \\
\hline 1000/Bulk & 51 & 112.06 & 109.160 & 84.40 & 22903 & 24349 & 1.063 \\
\hline 100/THF & 49 & 101.21 & 108.340 & 98.57 & 24100 & 31780 & 1.318 \\
\hline 200/THF & 48 & 189.00 & 105.230 & 92.64 & 23994 & 30234 & 1.254 \\
\hline 500/THF & 48 & 181.20 & 101.354 & 87.73 & 23234 & 30222 & 1.300 \\
\hline 1000/THF & 49 & 120.34 & 97.560 & 86.30 & 23092 & 29234 & 1.265 \\
\hline
\end{tabular}

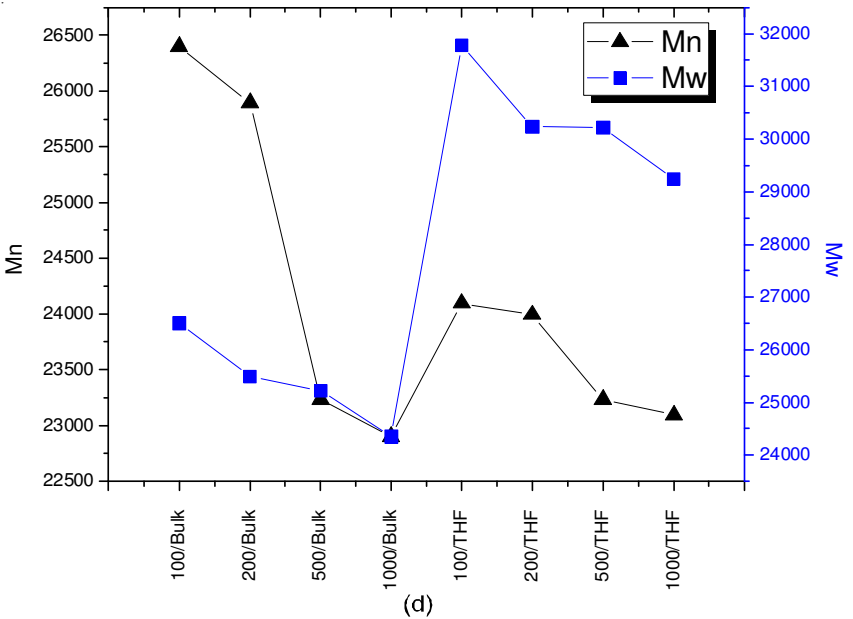

Fig. 3. Properties of synthesized PLA (a) Acid and hydroxyl value; (b) Saponification value and ester value; (c) Refractive index and viscosity; (d) Number average $\left(M_{n}\right)$ and weight average $\left(M_{w}\right)$ Molecular weight at different monomer to initiator ratio

and in solution that means molecular weight is increasing with increasing catalyst concentration in both bulk and in solution. Polydispersity index obtained narrow in range in bulk i.e. 1.42 to 1.40 and wide in range in solution i.e. 1.34 to 1.100 (Table-1). In Fig. 3 bulk polymerised PLA has quit high acid value (245 to 53) as compared to in solution polymerized PLA (163 to 95). Highest ester value and saponification value are 3292.55 and 3538.53 respectively in bulk and 2628 and 2173.29 respectively in solution. Highest ester and saponification value found at higher catalyst concentration in bulk. Refractive index of PLA polymerized in bulk was from 1.42 to 1.40 and in solution polymerized PLA has 1.32 to 1.298 . Polymer synthesized by this catalyst showed low viscosity 3.98 to 10.3 .

\section{Conclusion}

Synthesized N-methyl benzyl amine zirconium chloride compound is a five membered cyclometallic compound made by cyclometallation of secondary amine with zirconium oxychloride which effectively polymerized L-lactide to polylactide (PLA) via ring opening polymerisation. High molecular weight polylactide with low polydispersity indexed were obtained. Catalyst is in nanosize $(25-60 \mathrm{~nm})$, which can enhanced the rate of reaction. On increasing the monomer to catalyst ratio, $M_{n}$ and $M_{w}$ both are decreasing. Bulk polymerized PLA is high in $\mathrm{M}_{\mathrm{n}}$ as compared to in solution wheares in solution polymerized PLA has high in $\mathrm{M}_{\mathrm{w}}$. Polymer synthesized with the catalyst have low cost, high crystallinity, high yield, high viscosity with good refractive index in comparison with others polymer.

\section{REFERENCES}

1. A.K. Mohanty, L.T. Drzal and M. Manjusri, Natural Fibers, Biopolymers and Biocomposites, CRC Press, Francis and Taylor Group: Boca Raton, FL, p. 527 (2005).

2. R. Bhardwaj and A.K. Mohanty, Biomacromolecules, 8, 2476 (2007).

3. S.Q. Yin, M. Ji and R.S. Yao, Asian J. Chem., 25, 7561 (2013).

4. L. Jiang, M.P. Wolcott and J. Zhang, Biomacromolecules, 7, 199 (2006).

5. M. Vert, G. Schwarch and J. Coudane, J. Macromol. Sci.-Pure Appl. Chem. A, 32, 787 (1995).

6. D. Garlotta, J. Polym. Environ., 9, 63 (2001).

7. F. Chabot, M. Vert, S. Chapelle and P. Granger, Polymer, 24, 53 (1983).

8. M. Bero, J. Kasperczyk and Z.J. Jedlinski, Macromol. Chem., 191, 2287 (1990).

9. H.R. Kricheldorf and I. Kreiser, J. Macromol. Sci.-Pure Appl. Chem. A, 24, 1345 (1987).

10. J. Kasperczyk and M. Bero, Polymer, 41, 391 (2000).

11. A. Schindler and D. Harper, J. Polym. Sci. Polym. Chem. Edn, 17, 2593 (1979).

12. D. Mecerreyes, R. Jerome and P. Dubois, Adv. Polym. Sci., 147, 1 (1999).

13. J. Nieuwenhuis, Clin. Mater., 10, 59 (1992).

14. S.H. Kim, Y.K. Han, K.D. Ahn, Y.H. Kim and T. Chang, Makromol. Chem., 194, 3229 (1993).

15. J.W. Leenslag and A.J. Pennings, Makromol. Chem., 188, 1809 (1987).

16. J.M. Vion, R. Jerome, P. Teyssie, M. Aubin and R.E. Prudhomme, Macromolecules, 19, 1828 (1986).

17. D.W. Grijpma and A.J. Pennings, Polym. Bull., 25, 335 (1991).

18. A. Duda, S. Penczek, A. Kowalski and J. Libiszowski, Macromol. Symp., 153, 41 (2000).

19. M. Pfeffer, Pure Appl. Chem., 64, 335 (1992).

20. I.P. Beletskaya, A.V. Cheprakov, J. Organomet. Chem., 689, 4055, (2004).

21. A.T. Normand and K.J. Cavell, Eur. J. Inorg. Chem., 2781 (2008).

22. N. Selander and K.J. Szabo, Dalton Trans., 6267 (2009).

23. A.S. Goldman, A.H. Roy, Z. Huang, R. Ahuja, W. Schinski and M. Brookhart, Science, 312, 257 (2006).

24. D.C. Powers and T. Ritter, Nature Chem., 1, 302 (2009).

25. M. Albrecht and G. Koten, Adv. Mater., 11, 171 (1999).

26. Q. Zhao, T. Cao, F. Li, X. Li, H. Jing, T. Yi and C. Huang, Organometallics, 26, 2077 (2007).

27. A.D. Ryabov, V.S. Sukharev, L. Alexandrova, R. LeLagadec and M. Pfeffer, Inorg. Chem. 40, 6529 (2001).

28. P.J. Dyson and G. Sava, Dalton Trans. 1929 (2006).

29. S.A. Kurzeev, A.S. Vilesov, T.V. Fedorova, E.V. Stepanova, O.V. Koroleva, C. Bukh, M.J. Bjerrum, I.V. Kurnikov and A.D. Ryabov, Biochemistry, 48, 4519 (2009).

30. A.D. Ryabov, Chem. Rev., 90, 403 (1990).

31. W. Tsagkalidis, D. Rodewald and D. Rehder, Inorg. Chem. 34, 1943 (1995).

32. W. Tsagkalidis and D. Rehder, J. Biol. Inorg. Chem., 1, 507 (1996). 